\title{
Risk Factors for Postinduction Hypotension among Elderly Patients Undergoing Elective Non-Cardiac Surgery under General Anesthesia
}

\author{
Karuna Sutthibenjakul, M.D., Sunisa Chatmongkolchart, M.D. \\ Department of Anesthesia, Faculty of Medicine, Prince of Songkla University, Hat Yai, Songkhla 90110, Thailand. \\ Received 10 September 2020 • Revised 20 October 2020 • Accepted 23 October 2020 • Published online 31 March 2021
}

\begin{abstract}
:
Objective: We aimed to determine risk factors for hypotension occurring after induction among elderly patients (aged 65 years and older). We hypothesized that the dosage of intravenous anesthesia drugs as well as the type of inhalation agent have an effect on hypotension during post-induction periods. We aimed to test this hypothesis to determine risk factors for hypotension after induction among elderly patients who underwent non-cardiac surgery.

Material and Methods: This retrospective cohort study analyzed data from 580 patients between December 2017 and July 2018 at a tertiary university hospital in the south of Thailand. Hypotension is defined as a more than $30.0 \%$ decrease in mean arterial pressure from baseline after induction and within 20 minutes of the use of a vasopressor agent to treat hypotension. The intraoperative parameters were blood pressure and heart rate immediately after arrival at the operating room, immediately after intubation, and 5, 10, 15, and 20 minutes after intubation.

Results: The median age was $72.5(68,78)$ years. The association of post-induction hypotension was raised with a diuretic drug as preoperative medication ( $p$-value=0.025), and the degree of hypertension immediately after arrival at the operating room ( $p$-value<0.001). Increasing fentanyl dosage during induction was associated with hypotension (p-value<0.010). There was no statistically significant difference in the increase of the propofol dosage.
\end{abstract}

Conclusion: The degree of hypertension immediately after arrival at the operating room coupled with higher fentanyl dosage were significant risk factors for postinduction hypotension in elderly patients.

Keywords: elderly, hypotension, post-induction, risk factors

Contact: Karuna Sutthibenjakul, M.D.

Department of Anesthesia, Faculty of Medicine,

Prince of Songkla University, Hat Yai, Songkhla 90110, Thailand.

E-mail: aptx_conan@hotmail.com

2021 JHSMR. Hosting by Prince of Songkla University. All rights reserved.

This is an open access article under the CC BY-NC-ND license

(http://www.jhsmr.org/index.php/jhsmr/about/editorialPolicies\#openAccessPolicy).

J Health Sci Med Res 2021;39(5):391-400 doi: 10.31584 /jhsmr.2021795 www.jhsmr.org 


\section{Introduction}

There is evidence that hemodynamic instability during general anesthesia is associated with adverse outcomes in both, cardiac and non-cardiac surgery. ${ }^{1-3}$ General anesthesia induces hypotension, which commonly occurs in routine practice. An interval of general anesthesia can cause hypotension to occur. This includes the interval during the post-induction period starting from induction of general anesthesia until the beginning of surgery. ${ }^{4-6}$ General anesthesia induces a decrease in blood pressure (BP) via a variety of mechanisms such as the vasodilatation effect, which results in a drop in systemic vascular resistance, or hypovolemia. $^{7}$

The definition of hypotension is highly diverse. There is no accepted, single definition of intraoperative hypotension $(\mathrm{IOH})$. The incidence of $\mathrm{IOH}$ varies from 5 to $99.0 \%{ }^{8}$ Südfeld et al. ${ }^{6}$ defined post induction hypotension as: systolic blood pressure (SBP) $<90$ millimeter of mercury $(\mathrm{mmHg})$, or at least one incidence of norepinephrine infusion at a rate of $>6$ microgram $(\mathrm{mcg})$ per minute (20minute post-induction). Jor et al. ${ }^{9}$ defined hypotension as decreasing mean arterial pressure (MAP) of more than $30.0 \%$, compared to the baseline, which showed $36.5 \%$ had hypotension after induction of general anesthesia within the first 10 minutes after intubation.

With an increase in age comes the prediction that at some point a person may have to undergo some form of surgery. Perioperative morbidity most often occurs among the elderly; ${ }^{10}$ hence, increase in age is a predictor of intraoperative hypotension during the post-induction period. ${ }^{5,6,9,11}$

Nevertheless, there is insufficient information to predict which elderly patients are at risk for hypotension during the post-induction period. Reich et al. ${ }^{5}$ demonstrated that propofol induction and increases in fentanyl dosage are associated with hypotension within the first 10 minutes after induction. Previous studies revealed that increasing the dosage of propofol is associated with hypotension after induction, especially in patients over 70 years of age..$^{11}$ We hypothesized that the dosage of intravenous anesthesia drugs as well as the type of inhalation agent have an effect on hypotension during post-induction periods.

We aimed to test this hypothesis to determine risk factors for hypotension after induction among elderly patients who underwent non-cardiac surgery. The results of this study may predict hypotension after general anesthesia, and assist in the optimization of intraoperative BP.

\section{Material and Methods}

This retrospective cohort study was performed over a period of 8 months (from December 2017 to July 2018) at a tertiary university hospital in the south of Thailand. The proposal was approved by the Institute Ethics Committee, Faculty of Medicine, Prince of Songkla University (REC 61-260-8-1) and written informed consent was waived by the Institutional Review Board.

Inclusion criteria were:

1. Age 65 years and older undergoing elective non-cardiac surgery involving general anesthesia using endotracheal intubation and balanced technique.

2. American Society of Anesthesiologists (ASA) physical status I-IV.

Exclusion criteria were:

1. Combined general anesthesia with spinal or epidural anesthesia.

2. Two or more attempts with endotracheal intubation.

3. Patients who were intubated before surgery.

4. Vasopressor, or inotropic infusion before inducing general anesthesia.

5. Change in position of $\mathrm{BP}$ measurement during induction.

6. Deliberate hypotension within 20 minutes after intubation.

7. Incomplete data in medical records, including, systolic/diastolic BP and heart rate (HR) within 20 minutes after intubation. 
Our sample size was calculated based on a study by Reich et al. ${ }^{5}$ with the minimum study size being determined using 2 populations ( $\mathrm{n}$ for $2 \mathrm{p}$ ) in the R Foundation for Statistical Computing. A total of 579 patients were calculated as adequate to detect differences with $80.0 \%$ power and a two-tailed $\alpha$ error of $5.0 \%$.

Hypotension in this study is defined as more than a $30.0 \%$ decrease in MAP from baseline after induction and within 20 minutes, or the use of vasopressor agents to treat low BP. This definition is based on a study by Bijker et al. ${ }^{12}$ that demonstrated decreases in MAP of more than $30.0 \%$ from baseline are associated with the occurrence of ischemic stroke.

All data was collected from medical records, the electronic hospital information system and anesthetic records. We preoperatively recorded gender, age, weight, height, ASA classification, and comorbidity diseases (hypertension, diabetes mellitus, dyslipidemia, ischemic heart disease, cerebrovascular disease, end stage renal disease requiring hemodialysis and current medications (beta-blockers, calcium-channel blockers, angiotensin converting enzyme inhibitors, angiotensin receptor blockers, diuretics, insulin, oral antidiabetics and thyroid therapy)

Intraoperative parameters were: SBP, diastolic blood pressure (DBP), MAP, HR immediately after arrival at the operating room(T0), immediately after intubation (TEI), 5 minutes after intubation (T5), 10 minutes after intubation (T10), 15 minutes after intubation (T15) and 20 minutes after intubation (T20). BP was recorded every three to five minutes; either directly from an arterial catheter or using noninvasive methods.

Descriptive statistical results are displayed by the median and interquartile range $(\mathrm{IQR})$, or mean with standard deviation (S.D.) for continuous data and frequency, and with percentages for categorical data. Differences between non-hypotension and post-induction hypotension were evaluated with Ranksum tests, or t-tests, for continuous variables and Fisher's exact tests, or chi-square tests, for categorical data.

Factors associated with post-induction hypotension were determined using a multivariate logistical regression model. Measurements using Generalized Estimating Equations were utilized to evaluate blood pressure levels at various times. $\mathrm{R}$ software, version 3.5.1 ( $\mathrm{R}$ Foundation for Statistical Computing, Vienna, Austria), was used for data management and analysis. Statistical significance was assumed if the p-value was less than 0.050 .

\section{Results}

Patient selection is shown in the flow chart (Figure 1). A total of 580 subjects were included for end analysis.

Preoperative characteristics of patients to compare hypotension and non-hypotension groups are shown in Table 1. One hundred and ninety-six (33.8\%) patients had arterial catheter insertion. Three hundred and seventy-six $(64.8 \%)$ patients had hypotension at least one time within 20 minutes after intubation. However, four $(0.7 \%)$ patients had persistent hypotension from intubation to the first 20 minutes after intubation.

There were 39 (6.7\%), 132 (22.8\%), 193 (33.3\%), $230(39.7 \%)$ and $211(36.4 \%)$ subjects who had hypotension at TEI, T5, T10, T15 and T20, respectively (Table 2). Five hundred and seventy-four patients (98.9\%) received propofol as an intravenous induction drug, and five hundred and seventy-eight (99.6\%) patients received fentanyl as analgesia. The mean of propofol induction was 2.3 milligram per kilogram $(\mathrm{mg} / \mathrm{kg})$ and the mean of fentanyl induction was $1.7 \mathrm{mcg} / \mathrm{kg}$. After the induction period, $53.3 \%$ of patients received desflurane as an inhalation agent. The hypotension group had a higher age median of $73(68,79)$ years, while the median in the non-hypotension group was $71(68,76)$ years. 
Table 1 Demographic and clinical characteristics, comparing hypotension and non-hypotension groups

\begin{tabular}{|c|c|c|c|c|}
\hline Characteristics & $\begin{array}{l}\text { Total } \\
\text { Number (\%) }\end{array}$ & $\begin{array}{l}\text { Non-hypotension } \\
\text { Number (\%) }\end{array}$ & $\begin{array}{l}\text { Hypotension } \\
\text { Number (\%) }\end{array}$ & $\mathrm{p}$-value \\
\hline & $580(100.0)$ & 204 (35.2) & $376(64.8)$ & \\
\hline Sex & & & & 0.304 \\
\hline Male & $294(50.7)$ & $97(47.5)$ & $197(52.4)$ & \\
\hline Female & $286(49.3)$ & $107(52.5)$ & $179(47.6)$ & \\
\hline Age in years, median (IQR) & $72.5(68.0,78.0)$ & $71.0(68.0,76.0)$ & $73.0(68.0,79.0)$ & 0.026 \\
\hline 65-74 years & 348 & $134(38.5)$ & $214(61.5)$ & \\
\hline $75-84$ years & 191 & $61(31.9)$ & $130(68.1)$ & \\
\hline$\geq 85$ years & 41 & $9(22.0)$ & $32(78.0)$ & \\
\hline Weight $(\mathrm{kg})$ median (IQR) & $59.0(50.2,66.7)$ & $59.6(51.0,67.0)$ & $58.8(50.0,66.0)$ & 0.166 \\
\hline Height $(\mathrm{cm})$ median (IQR) & $158.0(150.0,165.0)$ & $157.5(150.0,164.0)$ & $158.0(150.0,165.0)$ & 0.786 \\
\hline BMI, median (IQR) & $23.4(20.7,26.5)$ & $23.8(21.2,26.6)$ & $23.2(20.6,26.2)$ & 0.169 \\
\hline ASA classification & & & & 0.389 \\
\hline II & $308(53.1)$ & $116(56.9)$ & $192(51.1)$ & \\
\hline III & $267(46.0)$ & $87(42.6)$ & $180(47.9)$ & \\
\hline IV & $5(0.9)$ & $1(0.5)$ & $4(1.1)$ & \\
\hline Comorbidity disease & $526(90.7)$ & $182(89.2)$ & $344(91.5)$ & 0.453 \\
\hline Hypertension & $373(64.3)$ & $129(63.2)$ & $244(64.9)$ & 0.759 \\
\hline Dyslipidemia & $237(40.9)$ & $88(43.1)$ & 149 (39.6) & 0.464 \\
\hline Cancer & $228(39.3)$ & 89 (43.6) & $139(37.0)$ & 0.139 \\
\hline Diabetes mellitus & $119(20.5)$ & $44(21.6)$ & 75 (19.9) & 0.723 \\
\hline Chronic heart disease & $113(19.5)$ & $38(18.6)$ & 75 (19.9) & 0.785 \\
\hline Ischemic heart disease & $51(8.8)$ & $18(8.8)$ & $33(8.8)$ & 1.000 \\
\hline End stage renal disease & $13(0.02)$ & $0(0.0)$ & $13(3.5)$ & 0.006 \\
\hline Preoperative medications & $388(66.9)$ & $130(63.7)$ & $258(68.6)$ & 0.270 \\
\hline Beta blockers & $126(21.7)$ & $36(17.6)$ & $90(23.9)$ & 0.099 \\
\hline Calcium channel blockers & $216(37.2)$ & 80 (39.2) & $136(36.2)$ & 0.526 \\
\hline ACE inhibitors & $70(12.1)$ & $21(10.3)$ & $49(13.0)$ & 0.405 \\
\hline ARBs & 75 (12.9) & $24(11.8)$ & $51(13.6)$ & 0.626 \\
\hline Diuretic & $75(12.9)$ & $20(9.8)$ & $55(14.6)$ & 0.128 \\
\hline Oral antidiabetic & $84(14.5)$ & $36(17.6)$ & $48(12.8)$ & 0.141 \\
\hline \multicolumn{5}{|l|}{ Pre-induction period, median (IQR) } \\
\hline Systolic (mmHg) & $160(140.0,170.2)$ & $150(135.0,165.0)$ & $160(145.0,180.0)$ & $<0.001$ \\
\hline Diastolic $(\mathrm{mmHg})$ & $80(70.0,90.0)$ & $75(70.0,80.0)$ & $80(70.0,90.0)$ & $<0.001$ \\
\hline Mean arterial pressure $(\mathrm{mmHg})$ & $105.5(97.0,115.0)$ & $100(92.0,108.0)$ & $110(98.8,117.0)$ & $<0.001$ \\
\hline Heart rate $(\mathrm{bpm})$ & $75(65.0,85.0)$ & $75(69.5,85.0)$ & $70(65.0,85.0)$ & 0.100 \\
\hline Hematocrit baseline (\%) mean (S.D.) & $36.3(5.2)$ & $36.8(4.9)$ & $36(5.3)$ & 0.083 \\
\hline Propofol (mg) median (IQR) & $120(100.0,160.0)$ & $130(100.0,170.0)$ & $120(100.0,160.0)$ & 0.200 \\
\hline Fentanyl (mcg) median (IQR) & $100(75.0,100.0)$ & $100(75.0,100.0)$ & $100(75.0,100.0)$ & 0.554 \\
\hline Desflurane & $309(53.3)$ & $102(50.0)$ & $207(55.1)$ & 0.281 \\
\hline Sevoflurane & $271(46.7)$ & $102(50.0)$ & $169(44.9)$ & 0.311 \\
\hline Nitrous oxide used & $4(0.7)$ & $1(0.5)$ & $3(0.8)$ & 1.000 \\
\hline
\end{tabular}

$\mathrm{kg}=\mathrm{kilogram}, \mathrm{cm}=$ centimeter, $\mathrm{BMI}=$ body mass index, IQR=interquartile range, ARBs=angiotensin receptor blockers, ACEls=angiotensin converting enzyme inhibitors, $\mathrm{mmHg}=$ millimeter of mercury, bpm=beat per minute, S.D.=standard deviation 


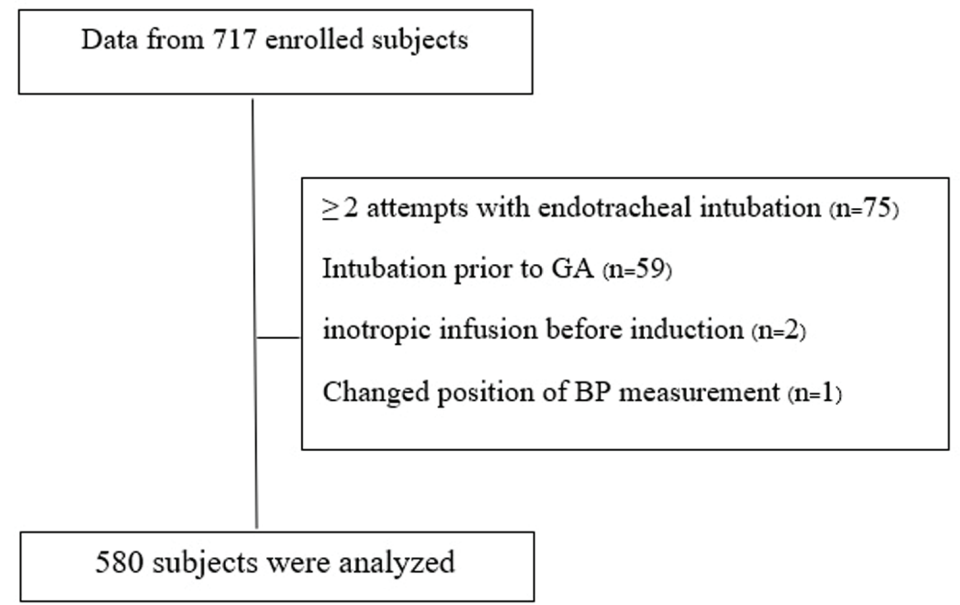

$\mathrm{GA}=$ general anesthesia, $\mathrm{BP}=$ blood pressure

Figure 1 Flow chart of patient enrollment

Table 2 Hypotension events at any time points within 20 minutes after induction period according to age groups

\begin{tabular}{lllllll}
\hline \multirow{2}{*}{ Age group } & \multicolumn{5}{c}{ Time points } \\
\cline { 2 - 6 } & TEI & T5 & T10 & T15 & T20 \\
\hline 65-74 years & 24 & 70 & 111 & 136 & 118 \\
$75-84$ years & 13 & 50 & 62 & 77 & 72 \\
$\geq 85$ years & 2 & 12 & 20 & 17 & 21 \\
Total (times) & 39 & 132 & 193 & 230 & 211 \\
\hline
\end{tabular}

TEl=time after intubation, $T 5=5$ minutes after intubation, $T 10=10$ minutes after intubation, $T 15=15$ minutes after intubation, T20=20 minutes after intubation

There was no statistically significant association between ASA classification, long term medication and the occurrence of post-induction hypotension. The median of SBP, DBP and MAP were higher in the hypotension group. All patients who had end stage renal disease with hemodialysis $(n=13)$ had hypotension at least at one time point after induction.

Figure 2 reveals the MAP median at every moment measured, at T0 it was 105 millimeters of mercury $(\mathrm{mmHg})$, then immediately after intubation, it slightly increased to 0.14 $\mathrm{mmHg}$, it then decreased from T0 to $18,24,25$, and 23 $\mathrm{mmHg}$ at T5, T10, T15 and T20, respectively. The lowest
MAP median was at 15 minutes after intubation. The T15 time point presented the highest incidence of postinduction hypotension, occurring in $39.7 \%$ of subjects.

Figure 3 reveals MAP from immediately arriving at the operating room (T0) up to 20 minutes after endotracheal intubation, according to age groups as well as aggregate plot median and IQR. There was no statistically significant difference between age groups.

Figure 4 presents intubation time for patients who received amounts of propofol less than or equal to 2.3 $\mathrm{mg} / \mathrm{kg}$, and fentanyl of more than $1.7 \mathrm{mcg} / \mathrm{kg}$, and had significant hypotension ( $p$-value=0.048). 


\section{Median and IQR of MAP during the induction and post induction}

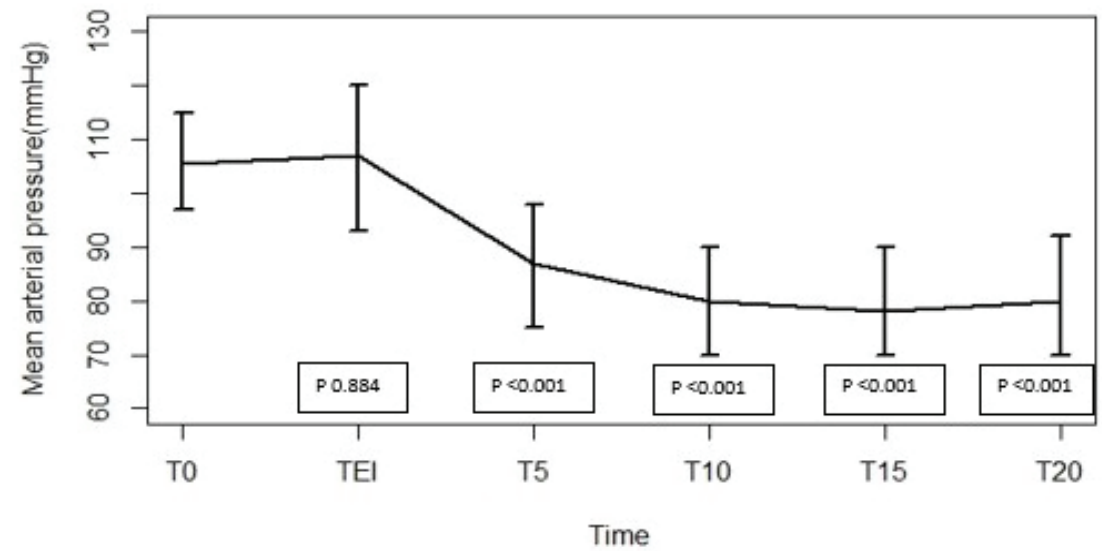

$\mathrm{IQR}=$ interquartile range, $\mathrm{MAP}=$ mean arterial pressure, $\mathrm{mmHg}=$ millimeter of mercury

T0=time after arrival at the operating room, TEI=time after intubation, T5=5 minutes after intubation, T10=10 minutes after intubation, T15=15 minutes after intubation, T20=20 minutes after intubation

Figure 2 Aggregate plot median and interquartile range of mean arterial pressure during the induction and post-induction

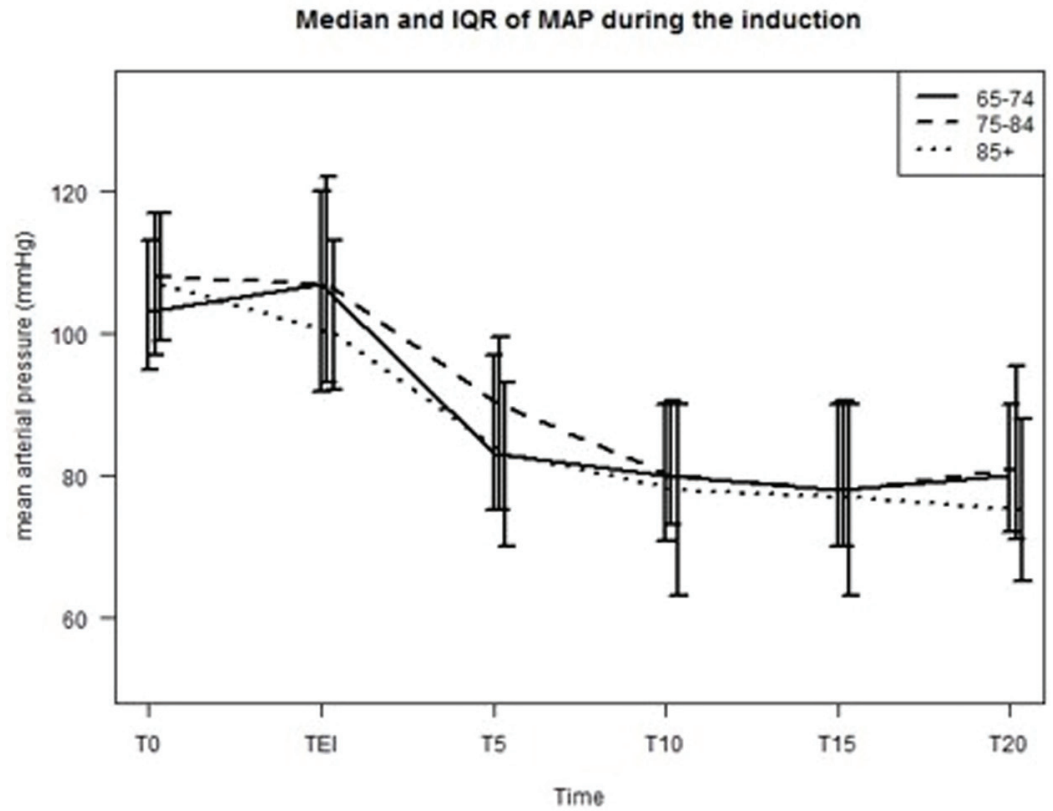

IQR=interquartile range, $\mathrm{MAP}=$ mean arterial pressure, $\mathrm{mmHg}=$ millimeter of mercury

T0=time after arrival at the operating room, TEl=time after intubation, T5=5 minutes after intubation, T10=10 minutes after intubation, T15=15 minutes after intubation, T20=20 minutes after intubation

Figure 3 Aggregate plot median and interquartile range of mean arterial pressure during the induction and post-induction by age groups 
Median and IQR of MAP during the induction by dose

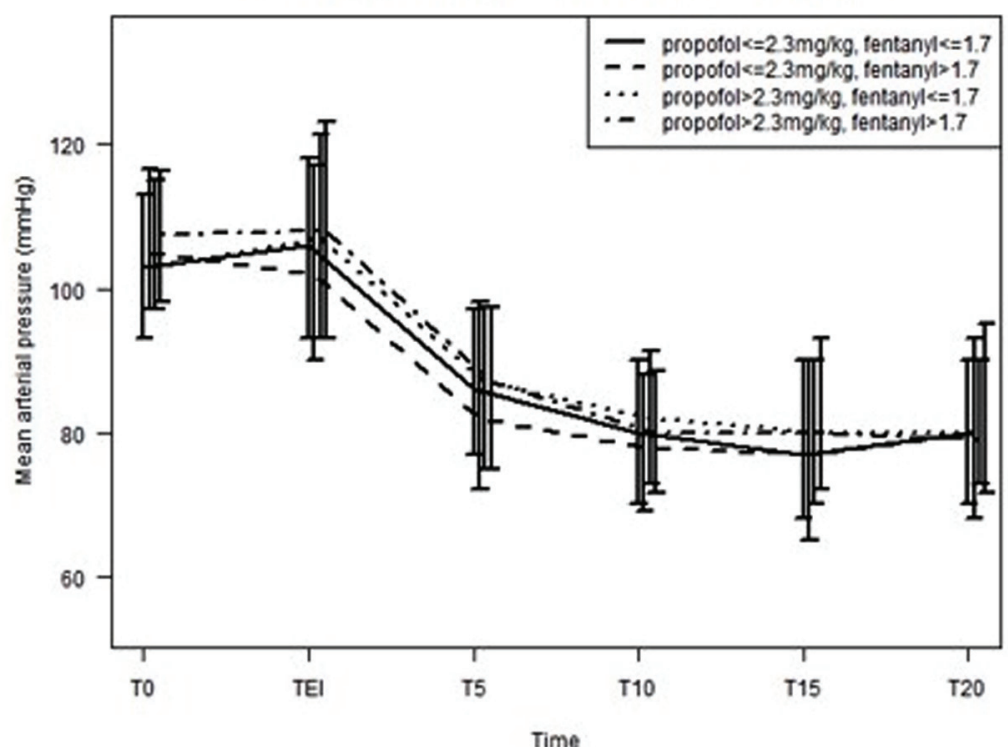

$\mathrm{IQR}=$ interquartile range, $\mathrm{MAP}=$ mean arterial pressure, $\mathrm{mmHg}=$ millimeter of mercury

T0=time after arrival at the operating room, TEl=time after intubation, T5=5 minutes after intubation, T10=10 minutes after intubation, T15=15 minutes after intubation, T20 $=20$ minutes after intubation

Figure 4 Aggregate plot median and interquartile range of mean arterial pressure during the induction and postinduction by dose propofol and fentanyl

Table 3 summarizes the multivariate logistic regression, which highlighted risk factors for hypotension for at least one time point. These included diuretic used as preoperative medication ( $p$-value $=0.025$ ), increased $\mathrm{BP}$ at pre-induction period ( $\mathrm{p}-\mathrm{value}<0.001)$ and heart rate baseline $(p-$ value $=0.018)$.
Multivariate logistic regression was associated with hypotension from intubation to 20 minutes after intubation. Increasing fentanyl dosage (every $10 \mathrm{mcg}$ ) was an associated risk of hypotension post-induction, especially at intubation time; odds-ratio (OR) 1.14, 95\% confidence interval (95\% Cl) 1.05-1.24, p-value<0.010) and 5 minutes after intubation (OR 1.15, 95\% Cl 1.09-1.23), p-value<0.001). There was no statistically significant difference in the propofol dosage. 
Table 3 Risk factors for hypotension at least one time point during 20 minutes after intubation, based on multivariate logistic regression

\begin{tabular}{|c|c|c|c|c|}
\hline Factors & crude OR $(95 \% \mathrm{Cl})$ & adj. OR $(95 \% \mathrm{Cl})$ & P (Wald's test) & $p$-value \\
\hline \multicolumn{5}{|l|}{ Age group } \\
\hline ref. $=65-74$ & & & & 0.251 \\
\hline 75-84 & $1.33(0.92,1.94)$ & $1.17(0.77,1.76)$ & 0.461 & \\
\hline $85+$ & $2.23(1.03,4.81)$ & $1.96(0.84,4.53)$ & 0.118 & \\
\hline Body mass index & $0.98(0.94,1.02)$ & $0.97(0.93,1.02)$ & 0.213 & 0.212 \\
\hline Diuretic as currently medication & $1.58(0.92,2.71)$ & $1.91(1.07,3.42)$ & 0.029 & 0.025 \\
\hline Pre-induction (DBP) & $1.04(1.03,1.06)$ & $1.04(1.02,1.06)$ & $<0.001$ & $<0.001$ \\
\hline Pre-induction heart rate & $0.99(0.98,1.00)$ & $0.98(0.97,1.00)$ & 0.019 & 0.018 \\
\hline Hematocrit baseline & $0.97(0.94,1.00)$ & $0.97(0.93,1.00)$ & 0.084 & 0.083 \\
\hline $\begin{array}{l}\text { Pre-induction (SBP) } \\
\text { ref. }=<139\end{array}$ & & & & $<0.001$ \\
\hline $140-159$ & $1.28(0.80,2.05)$ & $1.11(0.67,1.83)$ & 0.693 & \\
\hline $160-179$ & $2.20(1.37,3.53)$ & $1.61(0.96,2.70)$ & 0.073 & \\
\hline $180+$ & $4.94(2.70,9.05)$ & $3.33(1.72,6.44)$ & $<0.001$ & \\
\hline
\end{tabular}

$\mathrm{SBP}=$ systolic blood pressure, $\mathrm{DBP}=$ diastolic blood pressure, $\mathrm{OR}=$ odds ratio, $\mathrm{Cl}=$ confidence interval

\section{Discussion}

In this study, the definition of hypotension was based on the study by Bijker et al. ${ }^{12}$, which was a decrease in MAP of more than $30.0 \%$ compared to baseline and that significantly increases the risk of postoperative stroke. This study stands in contrast with a previous study by Südfeld et al. ${ }^{6}$, which had an incidence of post-induction hypotension of $18.1 \%$. The present study showed a higher incidence than the study by Jor et al. ${ }^{9}$ possibly due to the higher median age: $72.5(68,78)$ years, and the post-induction duration, which was 20 minutes, in contrast to $55(41,67)$ years, with the duration of post-induction being 10 minutes. Increasing age is a predictor of intraoperative hypotension during the post-induction period. ${ }^{5,6,9,11}$ Reich et al. ${ }^{5}$ presented that the incidence of hypotension was more frequent 5-10 minutes after induction, whereas, Jor et al. ${ }^{9}$ illustrated the highest occurrence of hypotension was observed within the first 5 and 10 minutes after intubation, while this study showed the time point at T15 having the highest incidence of post- induction hypotension. The reason why our study had a more delayed time point in hypotension than previous studies was because the subjects' ages were that of an elderly group, who had altered pharmacokinetic and pharmacodynamics. (decreased renal and hepatic function, decreased protein binding and altered volume of distribution). ${ }^{10}$

Reich et al. ${ }^{5}$ showed that risk factors for hypotension were: ASA III-IV, age $>50$ years, pre-induction MAP lower than $70 \mathrm{mmHg}$, use of propofol as an induction drug and high dosages of fentanyl (>5 mcg/kg). Jor et al. ${ }^{9}$ presented increased age, degree of hypertension at preinduction period and presence of diabetes as predictors of post-induction hypotension. Südfeld et al. ${ }^{6}$ revealed that independent variables for post-induction hypotension were: emergency surgery, increased age and pre-induction SBP. The results from Jor et al. ${ }^{9}$ were comparable to the results in this study because similar criteria for hypotension were used. Our results presented no statistically significant difference in increased age, or presence of diabetes. On 
the other hand, our study showed results in the degree of hypertension at the pre-induction period to be associated with the occurrence of post-induction hypotension. This may be explained by the high BP baseline during pre-induction, and the anesthesiologist may have preferred to decrease BP during induction, or also by the fact that vascular tone variation induces changes in $\mathrm{BP}$ in hypertensive patients so that BP may markedly decrease after general anesthesia. ${ }^{13}$

This study presents diuretics used as current medication to be associated with post-induction hypotension. In a previous study, by Anastasian et al. $^{14}$, it was shown that patients who took preoperative diuretic drugs required significantly more vasopressor in carotid endarterectomy surgery. However, a previous study by Khan et al. ${ }^{15}$ revealed, in a randomized control trial, that administration of furosemide on the day of surgery did not significantly increase intraoperative hypotension when compared with a placebo. Nevertheless, the present results may indicate that it is possible that the clinical indications for diuretic drugs may pose risks to the population that lean towards intraoperative hypotension.

Propofol dosage was not associated with postinduction hypotension because the difference in intravenous volume status for each patient may have disrupted the hypotension results. In a future study, a prospective method should be recorded.

The strength of this study was that there were many elderly patients who underwent general anesthesia. On the other hand, there were several limitations to our study. First, this study did not take into account the duration of hypotension episodes. A previous study revealed that longer durations of hypotension increase the risks of post-operative, acute kidney injury and myocardial injury. ${ }^{2}$ Secondly, it is unlikely that surgical stimulation started within the first 20 minutes after intubation, nevertheless, mildly stimulating procedures; such as, positional changes, or urinary catheterization may have occurred. Therefore, if there were any noxious stimuli during this period it may have influenced the incidence of hypotension. Thirdly, the pre-induction period is a time of anxiety, so BP and HR in this period may be higher than normal. Fourthly, the BP was intermittently measured for those who did not have an arterial catheter. Hypotension might have been missed between these interval measurements. Fifthly, the intravenous fluid and minimum alveolar concentration of inhalation agent these were given, were not recorded.

\section{Conclusion}

In conclusion, there continue to be several unanswered questions including what the optimal BP during the intraoperative period, and accurate BP may be. Our results provide evidence that the degree of hypertension at pre-induction period is a risk factor that is linked to hypotension in elderly patients after induction. Higher dosages of fentanyl are used in obtaining optimal BP for elderly patients who present with hypertension, or are at risk of developing hypotension. This evidence suggests that fentanyl ought to be used in lower dosages to avoid hypotension. Future research in this field, via a randomized control trial is necessary.

\section{Acknowledgement}

We would like to acknowledge to Prof. Virasakdi Chongsuvivatwong for his help in preparing this manuscript. Statistical analysis was also supported by Ms. Jirawan Jayuphan (Statistician at the Faculty of Medicine, Prince of Songkla University).

\section{Conflict of interest}

All authors declare there is no conflict of interest. 


\section{References}

1. Monk TG, Mangione MP, Nguyen JD, Hammermeister KE. Association between intraoperative hypotension and hypertension and 30-day postoperative mortality in noncardiac surgery. Multicenter Study 2015;123:307-19.

2. Walsh M, Devereaux PJ, Garg AX, Kurz A, Turan A, Rodseth $\mathrm{RN}$, et al. Relationship between intraoperative mean arterial pressure and clinical outcomes after noncardiac surgery: toward an empirical definition of hypotension. Anesthesiology 2013;119:507-15.

3. Reich DL, Bodian CA, Krol M, Kuroda M, Osinski T, Thys DM. Intraoperative hemodynamic predictors of mortality, stroke, and myocardial infarction after coronary artery bypass surgery. Anesth Analg 1999;89:814-22.

4. Ida M, Kimoto K, Iwata M, Nakayama K, Kamiya T, Kuzumoto $\mathrm{N}$, et al. Retrospective evaluation of predictors and frequency of hypotension in hypertensive patients after induction of general anesthesia. Masui 2014;63:614-8.

5. Reich DL, Hossain S, Krol M, Baez B, Patel P, Bernstein A, et al. Predictors of hypotension after induction of general anesthesia. Anesth Analg 2005;101:622-8.

6. Südfeld S, Brechnitz S, Wagner JY, Reese PC, Pinnschmidt $\mathrm{HO}$, Reuter DA, et al. Post-induction hypotension and early intraoperative hypotension associated with general anaesthesia. Br J Anaesth 2017;119:57-64.

7. Robinson BJ, Ebert TJ, O’Brien TJ, Colinco MD, Muzi M. Mechanisms whereby propofol mediates peripheral vasodilation in humans. Sympathoinhibition or direct vascular relaxation? Anesthesiology 1997;86:64-72.
8. Bijker JB, Klei WA van, Kappen TH, Wolfswinkel $L$ van, Moons KGM, Kalkman CJ. Incidence of intraoperative hypotension as a function of the chosen definition literature definitions applied to a retrospective cohort using automated data collection. Anesthes 2007;107:213-20.

9. Jor O, Maca J, Koutna J, Gemrotova M, Vymazal T, Litschmannova $\mathrm{M}$, et al. Hypotension after induction of general anesthesia: occurrence, risk factors, and therapy. A prospective multicentre observational study. J Anesth 2018;19:1-8.

10. Kanonidou Z, Karystianou G. Anesthesia for the elderly. Hippokratia 2007;11:175-7.

11. Cheung CC, Martyn A, Campbell N, Frost S, Gilbert K, Michota $F$, et al. Predictors of intraoperative hypotension and bradycardia. Am J Med 2015;128:532-8.

12. Bijker JB, Persoon S, Peelen LM, Moons KG, Kalkman CJ, Kappelle LJ, et al. Intraoperative hypotension and perioperative ischemic stroke after general surgery. Anesthesiology 2012;116:658-64.

13. Colson P, Gaudard P. Hypertension and anesthesia: what's new?. J Hypertens Manag 2016:2. doi: 10.23937/2474-3690/ 1510013.

14. Anastasian ZH, Gaudet JG, Connolly ES, Arunajadai S, Heyer EJ. The effect of antihypertensive class on intraoperative pressor requirements during carotid endarterectomy. Anesth Analg 2011;112:1452-60.

15. Khan NA, Campbell NR, Frost SD, Gilbert K, Michota FA, Usmani A, et al. Risk of intraoperative hypotension with loop diuretics: a randomized controlled trial. Randomized Controlled Trial 2010;123:1059.e1-8. 